\title{
Private Health Care Market Shaping and Equity in Childhood Diarrhea Treatment: Evidence From Data Analysis of an ORS and Zinc Scale-up Program in Eight States Across Nigeria
}

Tiwadayo Braimoh ( $\nabla$ tiwaday@yahoo.com )

Clinton Health Access Initiative, Kigali, Rwanda https://orcid.org/0000-0002-8791-4416

Isaac Danat

University of Wolverhampton Faculty of Education Health and Wellbeing

Mohammed Abubakar

Clinton Health Access Initiative

\section{Obinna Ajeroh}

Malaria Consortium

Melinda Stanley

Clinton Health Access Initiative

\section{Owens Wiwa}

Clinton Health Access Initiative

Marta Rose Prescott

Clinton Health Access Initiative

\section{Felix Lam}

Clinton Health Access Initiative

\section{Research}

Keywords: diarrhoea, oral rehydration salt (ORS), zinc treatment

Posted Date: October 29th, 2020

DOI: https://doi.org/10.21203/rs.3.rs-97224/v1

License: (c) (i) This work is licensed under a Creative Commons Attribution 4.0 International License. Read Full License

Version of Record: A version of this preprint was published at International Journal for Equity in Health on March 31st, 2021. See the published version at https://doi.org/10.1186/s12939-021-01425-2. 


\section{Abstract}

Background: Nearly 90,000 under-five children die from diarrhoea annually in Nigeria. Over $90 \%$ of the deaths can be prevented with oral rehydration salt (ORS) and zinc treatment but coverage nationally was less than $34 \%$ for ORS and $3 \%$ for zinc with wide inequities. A program was implemented in eight states to address critical barriers to the optimal functioning of the health care market to deliver these treatments. However, it has been argued that initiatives that engage the private sector may worsen inequities due to their profit motive.

Methods: Changes in disparities in the coverage of ORS and zinc treatments by socioeconomic strata and geographical location were assessed using data from cross-sectional baseline and endline surveys.

Results: At baseline, $28 \%$ (95\% Cl: 22 - 35\%) of children with diarrhoea from the poorest wealth quintile received ORS compared to $50 \%$ (95\% $\mathrm{Cl}: 52-58 \%)$ from the richest. This inequality reduced at endline as ORS coverage increased by $21 \%$-points $(P=0.000)$ for the poorest and $17 \%$-points $(P=0.000)$ for the richest. Zinc coverage increased significantly for both quintiles at endline from an equally low baseline coverage level. Consistent with the findings of the pairwise comparison of the poorest and the richest, the summary measure of disparity across all wealth quintiles showed a narrowing of inequities from baseline to endline. Concentration curves shifted towards equality for both treatments, concentration index declined from 0.1012 to 0.0480 for ORS and from 0.2640 to 0.0567 for zinc. Disparities in ORS and zinc coverage between rural and urban at both time points was insignificant except that the use of zinc in the rural at endline was significantly higher at $38 \%(95 \% \mathrm{Cl}$ : $35-41 \%)$ compared to $29 \%$ (95\% Cl: $25-33 \%)$ in the urban.

Conclusion: The results show a pro-rural improvement in coverage and a reduction in coverage inequities across wealth quintiles from baseline to endline. This gives an indication that initiatives focused on shaping healthcare market systems may be effective in reducing health coverage gaps without detracting from equity as a health policy objective.

\section{Introduction}

\section{Background}

Globally, diarrhoea is the second leading cause of death among children younger than five years, accounting for more than 800,000 child deaths each year (1). Nigeria, with nearly 90,000 under-five diarrhoea deaths is one of the top five countries in the world with the most deaths from this disease (2). Children from poor households suffer the most from diarrhoea due to unhygienic environment, lack of access to clean water and sanitation, and lack of access to nutritionally balanced diets (3).

The World Health Organization and United Nations Children Fund recommend the combination of oral rehydration salt (ORS) and zinc for the treatment of diarrhoea (4). ORS prevents dehydration, the primary mechanism by which diarrhoea leads to death, and zinc shortens the duration and prevents its reoccurrence in the two to three months following supplementation. The use of both medicines can prevent more than $90 \%$ of diarrhoea-related deaths among children $(5,6)$. However, only a small proportion of children in need of treatment receive these essential medicines and there are wide inequities across socioeconomic groups (7-11). Inequity refers to the unfair distribution of health determinants, outcomes, and resources within and between segments of a population (12-15). In Nigeria, less than $34 \%$ of children with diarrhoea received ORS and $3 \%$ received zinc in 
2013. The richest quintile had $165 \%$ higher treatment rates with ORS than those in the poorest quintile and nearly $60 \%$ more children in urban areas get treated with ORS as compared to rural children (16). Low-osmolarity ORS and zinc dispersible tablets (DT), the optimal formulations of ORS and zinc were largely unavailable.

In 2012, the Federal Ministry of Health and the National Primary Health Care Development Agency of Nigeria launched the Essential Childhood Medicines Scale-up Plan to reduce child mortality by increasing access to lifesaving treatments including zinc and ORS. The plan included private sector engagement in addition to traditional public sector interventions (17).

Between 2013 and 2017, the Clinton Health Access Initiative, Inc. (CHAl), with funding from the Norwegian Agency for Development Cooperation and Global Affairs Canada, supported the Government of Nigeria to implement a program to scale up ORS and zinc with focus on eight states, namely Bauchi, Cross River, Lagos, Kaduna, Kano, Katsina, Niger, and Rivers. A crucial aspect of the program was market-shaping the private sector. This implies addressing critical barriers and bottlenecks that prevent the commercial health care market system from functioning optimally to better reach populations at need $(18,19)$. However, it has been argued that initiatives that engage the private sector may be antithetical to the principles of equity $(20,21)$. Private sector as used here include pharmaceutical manufacturers, importers, and distributors of pharmaceuticals; private forprofit health providers; and retail pharmacies and informal drug stores.

\section{Program description}

A detailed description of the program has been published elsewhere (22). CHAl designed and implemented market shaping interventions to address the challenges that hamper availability, affordability and demand of optimal ORS and zinc products for childhood diarrhoea treatment.

The program collected and analysed market data to generate and share insights such as potential market size, competitive landscape and return on investment for ORS and zinc with manufacturers and importers in order to stimulate and guide their investment decisions regarding production, promotion, and sale of the products. To enable the updating of regulatory guidelines and facilitate product registration and market entry of the optimal products, relevant agencies of government were provided with the evidence and supported through the review process. Furthermore, suppliers were provided with technical assistance on cost reduction, for example through cost of goods sold analysis to identify lower cost inputs and packaging optimization. To improve rural availability, suppliers were incentivised through time-limited financial and technical support to develop distribution models that would sustainably reach underserved areas. For example, agreements were signed for the sharing of initial set up costs of rural sales force with the suppliers, contingent upon their meeting volume and reach targets. They were also supported with the development and implementation of innovative marketing and sales strategies. For example, wholesaler activation targeted retailers with merchandizing.

To increase demand, health care professionals and patent and proprietary medicines vendors (PPMVs) were trained and mentored on the correct treatment of childhood diarrhoea. The trainings were conducted once but three to four cycles of mentoring sessions were conducted through follow-up visits to individual providers by their specially trained peers to reinforce knowledge and entrench the right practices. PPMVs are largely informal medicine retailers but they are a dominant source of treatment for childhood illnesses, especially in underserved communities (16). Also, key influencers and various community networks were engaged to reach mothers and 
caregivers with messages on the right steps to take for children with diarrhoea. Finally, to engender competition and ensure a vibrant market, multiple suppliers were concurrently supported to enter the market. The number of low-osmolarity ORS products competing for market share increased to 35 from just one, and zinc DT increased to 12 and co-packs increased to 10 from zero during the program.

\section{Study objectives}

The purpose of this study is to examine how inequities in ORS and zinc coverage may have changed over the course of the program. The specific study objectives are: 1) To apply a range of measures of inequity with respect to population coverage of ORS and zinc for childhood diarrhoea and 2) To examine changes in these measures of inequity from program baseline to endline along the dimensions of geographical location and socioeconomic status of households

\section{Methods}

\section{Study Setting and Data Description}

Nigeria is the most populous country in Africa with population estimated at nearly 200 million (23). Children less than 5 years account for $17.6 \%$ of the population and $51 \%$ are from rural areas. There are wide wealth disparities across the country with the northern part of the country being the poorest. On the average, $54 \%$ of the population live below international poverty line of US\$1.25 per day (24). Nigeria operates a mixed system with a three-tiered public health system co-existing with a heterogenous private sector. The private sector provides about $60 \%$ of health service delivery (25). Nearly two-thirds of children are brought to PPMVs for treatment. The eights states where the program was implemented account for $40 \%$ of the burden of childhood diarrhoea (26). Three of the states are in the South and five are in the North of the country.

In low-and middle-income country (LMIC) settings, household surveys are usually the most reliable source of data for health inequality measurement and thus the most commonly used (12). As equity is technically unmeasurable but based on moral and ethical judgement about what is fair, the termed equality is used for measurements in this paper (12-15).

Details on the survey design have been published elsewhere (22). Briefly, data were collected using populationbased household surveys among caregivers of children under five and employing a random two-stage cluster sampling methodology. The baseline survey was conducted between December 2013 and November 2014 and the endline survey was conducted between April 2016 and May 2017. The surveys collected information on household characteristics including asset ownership, caregiver knowledge, care seeking behaviour, geographical location, caregiver and child sex and age, and treatment practices. The study used household asset data to construct wealth quintiles as a measure of socioeconomic status. Coverage is defined as the "percentage of children with diarrhoea in the two weeks preceding survey who were treated with ORS and zinc".

\section{Statistical analysis}

Stata version 14 (Stata Corp, College Station TX, USA) software was used in the first step of our analyses. We constructed wealth quintiles (poorest, second, middle, fourth, and richest) using principal component analysis of household assets. Wealth quintiles were used as a measure of socioeconomic status. Treatment coverage was defined as the percentage of children with diarrhoea in the two weeks preceding survey who were treated with 
ORS and zinc. We conducted descriptive statistics for characteristics of the child, caregiver, and household for each survey period. Chi-squared tests were used to compare characteristics and outcomes between baseline and endline surveys. We conducted multivariable logistic regression analysis to estimate how coverage changed between baseline and endline. Analyses were stratified by geographical location and socioeconomic status.

Microsoft Excel was used to compute simple absolute and relative disparities for pairwise comparisons and summary measures of inequality $(27,28)$. As socioeconomic status is comprised of ordered subgroups, a single comparison between the richest quintile and the poorest quintile was done, with the former being the reference group (12). Absolute disparities (AD) and relative disparities (RD) were determined as follows:

$A D=y 2-y 1$, where $y 2$ represent coverage in the reference group and $y 1$ refers to coverage in the comparison group.

$R D=y 2 / y 1$, where $y 2$ represent coverage in the reference group and $y 1$ represent coverage in the comparison group.

Concentration curves and indices were employed where the objective was to provide a summary measure across multiple subgroups, which was the case with socioeconomic status (29). Concentration curves provide a visual representation of inequality. Concentration curves above the hypothetical line of equality (45-degree line) implies that coverage is concentrated among the poor, below the line of equality mean that coverage is concentrated among the rich and along the line of equality implies equality between groups (30). Concentration curve was computed with the cumulative percentage of children treated with each of ORS and zinc plotted on yaxis and the cumulative percentage of the population of children with diarrhoea ranked by socioeconomic status, beginning with the poorest and ending with the richest plotted on the x-axis.

According to Wagstaff et al (1991), the concentration index is the most appropriate measure of health inequality since it reflects the experiences of the entire population and is sensitive to changes in the distribution of the population across subgroups (31). Defined as twice the area between the concentration curve and the line of equality, the concentration index (C.Index) was computed using the following formula (Fuller and Lury, 1977):

C.Index $=\left(\mathrm{P}_{1} \mathrm{~L}_{2}-\mathrm{P}_{2} \mathrm{~L}_{1}\right)+\left(\mathrm{P}_{2} \mathrm{~L}_{3}-\mathrm{P} 3 \mathrm{~L}_{2}\right)+\ldots+\left(\mathrm{P}_{\mathrm{T}-1} \mathrm{~L}_{\mathrm{T}}-\mathrm{P}_{\mathrm{T}} \mathrm{L}_{\mathrm{T}-1}\right)$

where $\mathrm{Pt}$ is the cumulative percentage of the sample ranked by economic status in group $\mathrm{t}$, and $\mathrm{Lt}$ is the corresponding concentration curve ordinate. $T$ is the number of socio-economic groups or wealth quintiles (30).

Concentration Index takes on values between -1 and +1 with 0 representing equality. The index quantifies the degree of relative inequality among subgroups and indicate the extent to which coverage is concentrated among the advantaged or disadvantaged. The larger the absolute value, the greater the disparity. A positive index is obtained when the curve lies below the diagonal $(C$.Index $>0)$ indicating that coverage is higher among the richer groups while a negative index is obtained when the curve lies above the diagonal $(\mathrm{C}$. Index $<0)$ indicating that coverage is higher among the poor (30).

\section{Results}

\section{Study Sample Characteristics}

Page 5/18 
The characteristics of surveyed households, caregivers and children have been described elsewhere (22). Except for a few exceptions, there was no statistically significant difference in sample characteristics between endline and baseline (Table 1). At endline, $22 \%(95 \% \mathrm{Cl}=20 \%, 24 \%)$ of diarrhoea episodes were among children 0-11 month compared to $12 \%(95 \% \mathrm{Cl}=10 \%, 15 \%)$ at baseline. At endline, $94 \%(95 \% \mathrm{Cl}=92 \%, 96 \%)$ of the caregiver respondents were female compared to $90 \%(95 \% \mathrm{Cl}=88 \%, 92 \%)$ at baseline. At endline, $55 \%(95 \% \mathrm{Cl}=51 \%, 59 \%)$ of diarrhoea episodes came from rural areas whereas at baseline the figure was $65 \%(95 \% \mathrm{Cl}=60 \%, 69 \%)$. It was also found that a lower proportion of diarrhoea episodes came from Rivers state $(P=0.05)$ and Bauchi state $(P=$ 0.03 ) at endline as compared to baseline. 
Table 1

Distribution of demographic and socioeconomic Characteristics by survey

\begin{tabular}{|c|c|c|c|}
\hline \multirow[t]{2}{*}{ Characteristics } & $\begin{array}{l}\text { Baseline } \\
(n=1661)\end{array}$ & $\begin{array}{l}\text { Endline } \\
(n=2268)\end{array}$ & \multirow[t]{2}{*}{$\begin{array}{l}\text { Endline vs. } \\
\text { Baseline } \\
\text { P-value }\end{array}$} \\
\hline & $\begin{array}{l}\text { Proportion (\%), } \\
\mathrm{Cl} *\end{array}$ & $\begin{array}{l}\text { Proportion (\%), } \\
\mathrm{Cl}\end{array}$ & \\
\hline
\end{tabular}

\section{Sex of Child}

Female

$48 \%(45-52 \%)$

$47 \%(45-49 \%)$

0.769

Age of Child (months)

$\begin{array}{llll}0-11 & 0.12(0.1,0.15) & 0.22(0.2,0.24) & 0.000 \\ 12-23 & 0.3(0.27,0.32) & 0.32(0.3,0.34) & 0.170 \\ 24-35 & 0.19(0.17,0.22) & 0.23(0.21,0.25) & 0.083 \\ 36-47 & 0.19(0.17,0.22) & 0.15(0.13,0.17) & 0.005 \\ 48-59 & 0.20(0.17,0.22) & 0.09(0.08,0.1) & 0.000\end{array}$

\section{Source of care}

Did not seek care or advice outside the home $\quad 0.34(0.3,0.38) \quad 0.27(0.25,0.3) \quad 0.005$

$\begin{array}{llll}\text { Source care in public sector } & 0.25(0.22,0.28) & 0.27(0.24,0.3) & 0.436\end{array}$

$\begin{array}{llll}\text { Source care in private sector } & 0.34(0.3,0.38) & 0.38(0.35,0.41) & 0.093\end{array}$

$\begin{array}{llll}\text { Source care in other place } & 0.02(0.01,0.03) & 0.03(0.02,0.04) & 0.200\end{array}$

$\begin{array}{llll}\text { Source care from multiple sectors } & 0.05(0.04,0.07) & 0.05(0.04,0.07) & 0.901\end{array}$

\section{Sex of respondent/child caregiver}

Female

$0.90(0.88,0.92)$

$0.94(0.92,0.96)$

0.013

Age (years) of respondent/chil's caregiver

\begin{tabular}{llll}
\hline $15-19$ & $0.04(0.03,0.06)$ & $0.03(0.02,0.04)$ & 0.027 \\
\hline $20-29$ & $0.49(0.45,0.53)$ & $0.53(0.5,0.56)$ & 0.122 \\
\hline $30-39$ & $0.31(0.27,0.34)$ & $0.33(0.3,0.36)$ & 0.325 \\
\hline $40-49$ & $0.11(0.08,0.15)$ & $0.08(0.06,0.09)$ & 0.035 \\
\hline $50-59$ & $0.03(0.02,0.05)$ & $0.02(0.02,0.04)$ & 0.482 \\
\hline $60+$ & $0.02(0.01,0.03)$ & $0.01(0.01,0.02)$ & 0.310 \\
\hline $\begin{array}{l}\text { Child's caregiver attended any level of } \\
\text { schooling }\end{array}$ & $0.51(0.46,0.55)$ & $0.56(0.52,0.61)$ & 0.056
\end{tabular}

\section{Residence of Household}

Rural

$0.65(0.6,0.69) \quad 0.55(0.51,0.59) \quad 0.002$ 


\begin{tabular}{|c|c|c|c|}
\hline Characteristics & $\begin{array}{l}\text { Baseline } \\
(n=1661) \\
\text { Proportion (\%), } \\
\text { Cl* }\end{array}$ & $\begin{array}{l}\text { Endline } \\
(\mathrm{n}=2268) \\
\text { Proportion (\%), } \\
\text { Cl* }\end{array}$ & $\begin{array}{l}\text { Endline vs. } \\
\text { Baseline } \\
\text { P-value }\end{array}$ \\
\hline \multicolumn{4}{|c|}{ Size of household } \\
\hline $2-4$ & $0.29(0.26,0.33)$ & $0.32(0.29,0.35)$ & 0.548 \\
\hline $5-7$ & $0.39(0.35,0.43)$ & $0.4(0.38,0.43)$ & 0.104 \\
\hline $8-10$ & $0.18(0.16,0.21)$ & $0.16(0.13,0.18)$ & 0.420 \\
\hline $11+$ & $0.13(0.11,0.16)$ & $0.12(0.1,0.15)$ & 0.384 \\
\hline \multicolumn{4}{|c|}{ State where program was implemented } \\
\hline Lagos & $0.08(0.05,0.12)$ & $0.11(0.09,0.13)$ & 0.268 \\
\hline Kano & $0.21(0.17,0.25)$ & $0.23(0.2,0.27)$ & 0.309 \\
\hline Rivers & $0.10(0.08,0.13)$ & $0.06(0.04,0.08)$ & 0.005 \\
\hline Bauchi & $0.14(0.12,0.18)$ & $0.10(0.07,0.13)$ & 0.030 \\
\hline Cross River & $0.07(0.05,0.09)$ & $0.06(0.05,0.07)$ & 0.794 \\
\hline Kaduna & $0.14(0.1,0.18)$ & $0.16(0.13,0.19)$ & 0.399 \\
\hline Katsina & $0.14(0.12,0.17)$ & $0.16(0.13,0.18)$ & 0.454 \\
\hline Niger & $0.12(0.1,0.15)$ & $0.13(0.11,0.15)$ & 0.495 \\
\hline \multicolumn{4}{|c|}{ Wealth quintiles of households } \\
\hline Poorest & $0.20(0.17,0.24)$ & $0.22(0.19,0.26)$ & 0.446 \\
\hline Second & $0.19(0.16,0.23)$ & $0.21(0.19,0.24)$ & 0.422 \\
\hline Middle & $0.20(0.16,0.24)$ & ) $.22(0.19,0.24)$ & 0.538 \\
\hline Fourth & $0.19(0.16,0.23)$ & ) $.18(0.16,0.22)$ & 0.723 \\
\hline Richest & $0.21(0.17,0.26)$ & $0.17(0.14,0.2)$ & 0.092 \\
\hline
\end{tabular}

\section{ORS and zinc treatment coverage among children with diarrhoea by subgroups}

Table 2 presents coverage by geographical location and socioeconomic status. From baseline to endline. ORS coverage increased by 18 percentage points $(P=0.000)$ in rural but improvements for urban (6 percentage points) was not statistically significant $(P=0.210)$. Conversely, zinc coverage increased significantly for both rural and urban from baseline to endline. Across wealth quintiles, ORS coverage increased significantly from baseline to endline except for the middle quintile with 4 percentage points increase $(P=0.462)$ and fourth quintile with 7 percentage points $(P$-value $=0.242)$. For zinc, coverage increased significantly for all quintiles. 
Table 2

ORS and zinc treatment coverage by subgroup

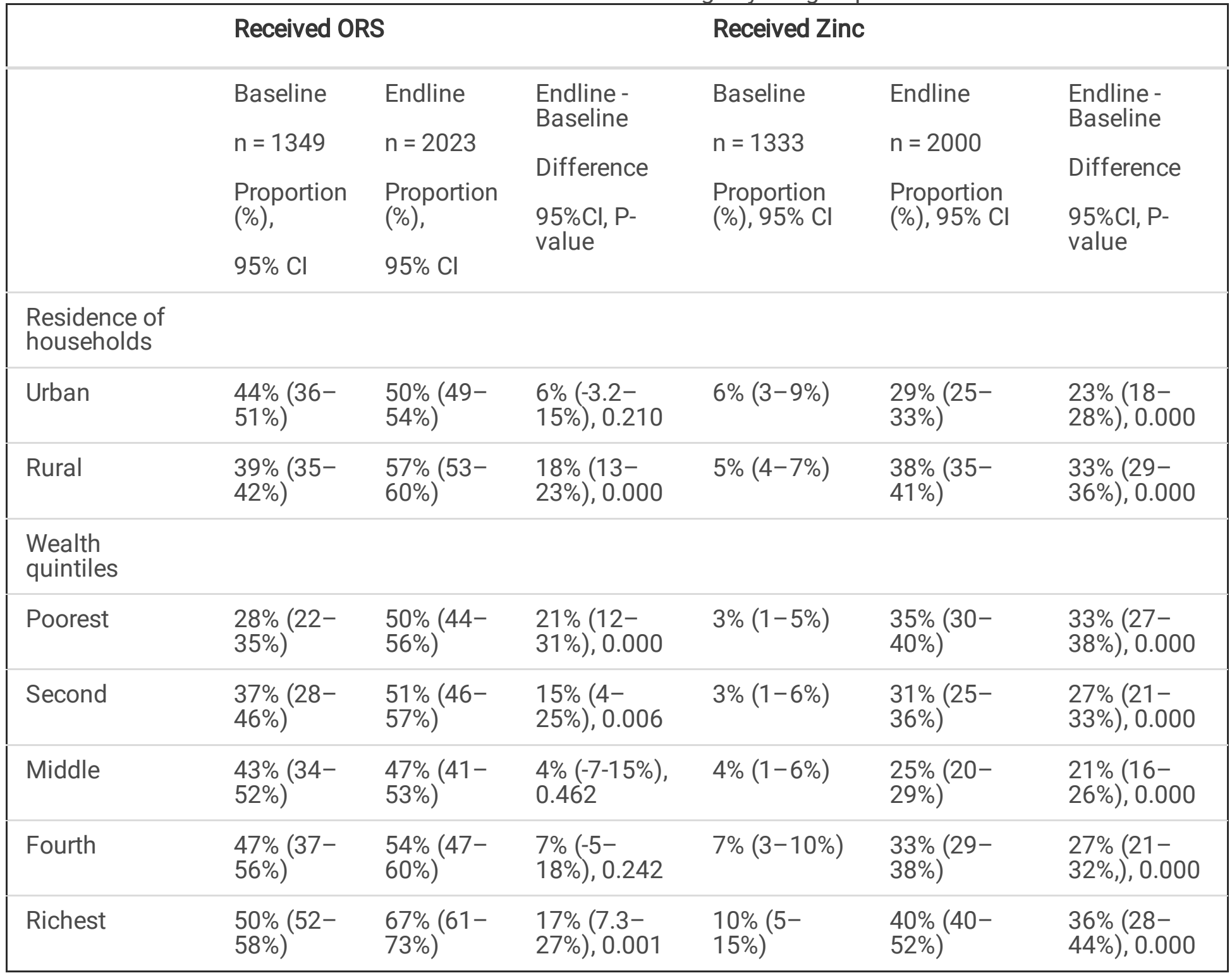

\section{Inequalities in ORS and zinc treatment coverage}

\section{Geographical location}

For both ORS and zinc, absolute and relative disparity measures show pro-urban skewness at baseline, but this was reversed in favour of rural at endline (Table 3). However, the disparities in both time points were not statistically significant except for zinc which had a coverage of $38 \%(95 \% \mathrm{Cl}=35-41 \%)$ in the rural and $29 \%$ $(95 \% \mathrm{Cl}=25-33 \%)$ in the urban at endline (Tables 2$)$. 
Table 3

Disparities in ORS and zinc treatment coverage for children with diarrhoea in urban versus rural households.

\begin{tabular}{|c|c|c|c|c|c|c|c|c|}
\hline & ORS & & & & zinc & & & \\
\hline \multirow[t]{3}{*}{ Time } & \multicolumn{2}{|c|}{$\begin{array}{l}\text { Treatment } \\
\text { Coverage }\end{array}$} & \multirow{3}{*}{$\begin{array}{l}\text { Difference } \\
\text { \% points } \\
\text { (Urban - } \\
\text { Rural) }\end{array}$} & \multirow{3}{*}{$\begin{array}{l}\text { Ratio } \\
\text { (Urban/Rural) }\end{array}$} & \multirow{2}{*}{\multicolumn{2}{|c|}{$\begin{array}{l}\text { Treatment } \\
\text { Coverage } \\
\%\end{array}$}} & \multirow{3}{*}{$\begin{array}{l}\text { Difference\% } \\
\text { points } \\
\text { (Urban - } \\
\text { Rural) }\end{array}$} & \multirow{3}{*}{$\begin{array}{l}\text { Ratio } \\
\text { (Urban/Rural) }\end{array}$} \\
\hline & \multicolumn{2}{|l|}{$\%$} & & & & & & \\
\hline & Urban & Rural & & & Urban & Rural & & \\
\hline Baseline & 43.81 & 38.51 & 5.30 & 1.14 & 5.58 & 5.16 & 0.42 & 1.08 \\
\hline Endline & 49.55 & 56.78 & -7.23 & 0.87 & 28.59 & 37.80 & -9.21 & 0.76 \\
\hline
\end{tabular}

\section{Socioeconomic status}

There were wide disparities in ORS coverage between wealth quintiles at baseline. The poorest had a significantly lower coverage of $28 \%(95 \% \mathrm{Cl}=22-35 \%)$ as compared to the fourth quintile with $47 \%(95 \% \mathrm{Cl}=$ $37-56 \%)$ and richest with $50 \%(95 \% \mathrm{Cl}=52-58 \%)$. However, the magnitude of coverage increase from baseline to endline was higher for the poorest, resulting in the narrowing of disparity gaps at endline (Table 2). Pairwise comparisons of the richest and the poorest show a decline in absolute disparity for ORS from 21 percentage points at baseline to 17 percentage points at endline. In relative terms, the richest had $76 \%$ higher coverage at baseline but at endline, the advantage over the poorest declined to 34\% (Table 4). In the case of zinc, absolute and relative disparities went different directions. Absolute disparities for zinc was higher (11\%) at endline relative to baseline (7\%), both in favour of the richest. In contrast, the relative disparity for zinc decreased from a richest/poorest ratio of 3.5 to 1 at baseline to a ratio of 1.3 to 1 at endline (Table 4).

Table 4

absolute and relative disparities between the richest and the poorest socioeconomic groups

\begin{tabular}{|c|c|c|c|c|c|c|c|c|}
\hline & \multirow[t]{2}{*}{ 冫 } & \multicolumn{5}{|c|}{ Treatment Coverage } & \multirow{2}{*}{$\begin{array}{l}\text { Difference } \\
\text { \% points }\end{array}$} & \multirow[t]{2}{*}{ Ratio } \\
\hline & & Poorest \% & Second \% & Middle \% & Fourth \% & Richest \% & & \\
\hline \multirow[t]{2}{*}{ ORS } & Baseline & 28.38 & 36.63 & 42.86 & 46.8 & 49.82 & 21.44 & 1.76 \\
\hline & Endline & 49.87 & 51.39 & 46.89 & 53.5 & 67.03 & 17.16 & 1.34 \\
\hline \multirow[t]{2}{*}{ zinc } & Baseline & 2.81 & 3.4 & 3.6 & 6.7 & 9.89 & 7.08 & 3.52 \\
\hline & Endline & 35.47 & 30.6 & 24.57 & 33.32 & 46.01 & 10.54 & 1.30 \\
\hline
\end{tabular}

Figure 1 shows concentration curve for ORS coverage. At baseline, the curve lies below the 45-degree line (line of equality) implying that coverage was concentrated among the rich. At endline the curve moved closer to the line of equality, implying that coverage became more equally distributed within the wealth subgroups. The concentration index for ORS at baseline was 0.1012 indicating a pro-rich skew in coverage. At endline, the concentration index was 0.048 indicating that coverage across wealth quintiles became closer to equality, though it shows that coverage is still slightly to the advantage of the rich (27).

Figure 2 shows concentration curve for zinc coverage. The curve at baseline lie farther below the line of equality meaning that coverage was concentrated among the rich. At endline, it moved to roughly overlap the line of 
equality implying a shift towards coverage equality across wealth quintiles. In congruence with the curves, the concentration index changed from 0.264 at baseline to 0.057 at endline, implying a shift towards equality, but there was still a slight skewness of coverage in favour of the rich.

\section{Discussion}

The results show a pro-rural improvement in coverage and a reduction in coverage inequality between wealth quintiles from baseline to endline for both products. The seeming conflict in the result of the pairwise comparison of zinc coverage for the poorest and richest was resolved as a closer look at Table 4 reveals poor baseline values for both wealth quintiles. The high relative disparity at baseline only reflects the relative scale of coverage despite the low coverage for both quintiles. This result tend to support arguments for the use of multiple measures to enable more accurate interpretation of equity analysis (32). As reasoned by O'Donnell et al (2008), equity is an important health policy goal, but the average level of health should not be overlooked (33).

Disparities in treatment coverage for childhood diarrhoea in Nigeria along the axis of geographical location and income have been documented (24). Although urban-rural disparities were found to be statistically nonsignificant except for zinc at endline, the direction of the inequalities obtained from the pairwise comparisons were similar to that of the richest and poorest groups. This is consistent with the report by Doherty et al (2015) that inequities arising from socioeconomic status are closely associated with geographical dimension of disparities (34).

As wealth subgroups have a natural ordering, the single comparison using absolute and relative measures between the richest and the poorest leaves out the three middle quintiles. This justified the use of concentration curves and indices. For each of ORS and zinc, the concentration curves demonstrate a considerable deviation from equality at baseline. It is evident from the graph that progress was made in narrowing of equity gaps over the intervention period.

The concentration curves gave a visual representation of a reduction in inequality across the wealth quintiles and the indices indicated the magnitude of the decline towards zero. While the cut off for concentration index is often based on social value judgement, an absolute value greater than 0.2 is considered to represent a high level of relative inequality (12). Zinc had a higher relative inequality at baseline as compared to ORS, but the number of children affected by ORS inequality was greater. Examining both the concentration curves and indices in conjunction with the simple measures, one can ensure that no information is lost (30).

This finding corroborates other studies documenting reductions in inequalities in childhood diarrhoea treatment coverage after targeted interventions. Larson et al (2009) reported on the efforts to deliver zinc at scale in Bangladesh through the "Scaling Up of Zinc for Young Children (SUZY)" project and concludes that there was an increase in zinc coverage over time and a reduction in gaps based on income status (35).

The decline in inequality levels may have been driven by the approach of targeting interventions such as the training and mentoring of PPMVs, the predominant provider for disadvantaged populations (36). A systematic review published in 2014 reported that interventions that were effective in reducing inequity among different sociodemographic groups included those that use human resources nearest to residents at the community level (37). Without targeting, health interventions tend to be adopted initially by the wealthiest, and later trickle down to the rest of the population (38-40)

Page $11 / 18$ 
Notwithstanding, there are legitimate concerns about a reliance on the private sector for population health needs. Some argue that they do not have equity as an objective and often locate where willingness to pay is greatest $(18,35)$. Studies have shown that urban and wealthier households disproportionately use the private sector compared to rural and poorer households $(41,42)$. Conversely, low quality private service provision such as the case of informal providers in rural areas of low-income settings are used disproportionately by the poor (43).

Some proponents of private sector engagement argue for the use of regulation to address these drawbacks but Montagu and Goodman (2016) reasoned that regulation alone can be ineffective in contexts where there is a dearth of credible alternatives to what is being regulated (44). Moreover, many LMIC country governments lack capacity to provide effective regulation (43). Market shaping can be effective since it identifies and addresses contextual constraints to harnessing private sector potentials for public health in supportive manner. For example, it was reported that in Tanzania, medicines produced locally were found to be more likely than imported products to be available to rural dwellers (45). In such situation, market shaping intervention to optimize local manufacture would be an effective approach.

The limitations of this study have been discussed in detail elsewhere (46). In addition, the data used in this study had socioeconomic status of households determined using principal component analysis (PCA) which has been criticized for a number of reasons: Filmer and Pritchett (2001) argued that it reflects long-run family wealth but fail to take into account temporary interruptions to living standards and Falkingham and Namazie (2002) reasoned that ownership does not always capture the quality of assets. There have also been arguments that it assesses only relative rather than absolute socioeconomic status (McKenzie, 2003). Despite the seeming limitations, the large magnitude of observed changes and the consistency of the result when compared to studies in different populations, appear to suggest that the intervention is probably responsible for the outcomes.

The findings of this study have implications for policy. First, it is important for governments and other actors in global health to know and be proactive to take hold of unutilized contextual levers that have the potential of complementing traditional approaches to deliver high-impact results for those in pressing need. However, while market shaping interventions can be employed in the short run to surmount critical health access challenges, governments should not abdicate their responsibilities of stewarding and ensuring that health programs do not deviate from health policy objectives. Second, although seemingly effective, market shaping programs should not be taken as substitutes to a deliberate effort at building robust and sustainable health systems that meet the health needs of everyone irrespective of their ability to pay. Third, mainstreaming equity considerations into health policies and programmes can help to speed up progress towards universal health coverages. However, undue emphasis on equity to the detriment of overall improvements of outcomes should be avoided. And finally, to target interventions to disadvantaged populations is not the same as addressing the underlying determinants of inequities. Governments must acknowledge and tackle the structural obstacles to equitable access to healthcare to adequately address the unjust differences in health utilization and outcomes.

\section{Conclusions}

This study aimed to contribute to evidence as to whether market shaping interventions in public health programs help to move towards or detracts from equitable treatment coverage for childhood diarrhoea in Nigeria. The results show a pro-rural improvement in coverage and a reduction in coverage inequities across wealth quintiles

Page $12 / 18$ 
from baseline to endline. This gives an indication that initiatives focused on shaping healthcare market systems may be effective in reducing health coverage gaps without detracting from equity as a health policy objective.

\section{Declarations}

\section{Ethical approval}

The study was reviewed and approved by the National Health Research Ethics Committee of Nigeria (NHREC) (protocol number NHREC/01/01/2007). Ethical approval was also obtained from each state government research ethics committee. Written informed consent was obtained from all participating respondents.

\section{Consent for publication}

Not applicable

\section{Availability of data and materials}

Data are available from the authors upon reasonable request and with permission of Clinton Health Access Initiative

\section{Competing interest}

All authors were or are employees of the Clinton Health Access Initiative and received funding to design, implement, and evaluate the program from the which the data for this study was generated. The authors declare that they have no additional competing interests.

\section{Acknowledgements}

The authors would like to thank the Norwegian Agency for Development Cooperation and Global Affairs Canada for funding support. Thanks to Dr. Timothy Powell-Jackson, Associate Professor in Health Economics, Department of Global Health and Development, Faculty of Public Health and Policy, London School of Hygiene and Tropical Medicine for his inputs.

\section{Funding}

The program implementation and evaluation were funded by grants from the Norwegian Agency for Development Cooperation and Global Affairs Canada. The funding organization did not have any part in data analysis or the preparation of this publication

\section{Authors' Contributions}

TB analysed and interpreted the data and wrote the manuscript, FL was a major contributor in the analysis of data and writing of the manuscript, ID reviewed and made inputs to the manuscript, and FL and MA were 
involved in primary data collection. All authors read and approved the final manuscript.

\section{References}

1. Liu L, Johnson HL, Cousens S, Perin J, Scott S, Lawn JE, et al. Global, regional, and national causes of child mortality: An updated systematic analysis for 2010 with time trends since 2000. Lancet [Internet]. 2012;379(9832):2151-61. Available from: http://dx.doi.org/10.1016/S0140-6736(12)60560-1

2. Liu, L. et al. Global, regional, and national causes of under-5 mortality in 2000-15: an updated systematic analysis with implications for the Sustainable Development Goals. Lancet. 2016;(388(10063)):3027-3035.

3. Keusch GT, Fontaine O, Bhargava A, Boschi- C, Bhutta ZA, Gotuzzo E, et al. Chapter 19 Diarrheal Diseases. 2001;371-87.

4. WHO/UNICEF joint statement: Clinical management of acute diarrhoea. 2004.

5. Munos, M.K., C.L. Walker and REB. The effect of oral rehydration solution and recommended home fluids on diarrhoea mortality. Int J Epidemiol. 2010;(39 Suppl 1):i75-87.

6. Lazzerini M and HW. Oral zinc for treating diarrhoea in children. Cochrane Database Syst Rev. 2016; (12):CD005436.

7. T. Wardlaw, P. Salama, C. Brocklehurst, M. Chopra A, Mason E. Diarrhoea:Why children are still dying and what can be done. Lancet. 2010;375(9718):870-872.

8. Rockers PC, Laing RO, Wirtz VJ. Equity in access to non-communicable disease medicines: a cross-sectional study in Kenya. BMJ Glob Heal [Internet]. 2018;3(3):e000828. Available from:

http://gh.bmj.com/lookup/doi/10.1136/bmjgh-2018-000828

9. LeFevre AE, Mohan D, Mazumder S, Lamberti LL, Taneja S, Black RE, et al. Diarrhea no more: does zinc help the poor? Evidence on the effectiveness of programmatic efforts to reach poorest in delivering zinc and ORS at scale in UP and Gujarat, India. J Glob Health [Internet]. 2016;6(2). Available from: http://jogh.org/documents/issue201602/jogh-06-021001.pdf

10. Vialle-Valentin CE, Serumaga B, Wagner AK, et al. Evidence on access to medicines for chronic diseases from household surveys in five low- and middle-income countries. Health Policy Plan 2015;30:1044-52.

11. Bigdeli M, Jacobs B, Tomson G, et al. Access to medicines from a health system perspective. Health Policy Plan 2013;28:692-704.

12. WHO. Health Inequality Monitoring. 2013;126. Available from: file:///C:/Users/M/Desktop/articulos/Health Inequality Monitoring with a Special Focus on Low-and Middle- Income Countries.pdf

13. Working definition from the CDC Health Equity Working Group, October 2007.

14. http://www.who.int/hia/about/glos/en/index1.html.

15. Peter F, Evans T. Ethical dimensions of health equity. In: Evans T, Whitehead M, Diderichsen F, Bhuiya A, Wirth M, editors. Challenging Inequities in Health: From Ethics to Action. New York: Oxford, 2001, 25-33.

16. NDHS. Nigeria Demographic and Health Survey 2013. Niger Demogr Heal Surv 2013 Natl Popul Comm Fed Repub Niger. 2013;201-21.

17. Federal Ministry of Health, National Primary Health Care Development Agency [Nigeria], "Essential childhood medicines scale-up plan: 2012-2015," 2012. [Online] Available: ht_tp:// ccmcentral.com/wpcontent/uploads/2016/01/c.-Nigeria_ 733 Essen. 
18. Increasing Access to Essential Health Commodities and Services Scoping study for the UK Department for International Development on the potential role of development capital. 2015;(September).

19. Amy L, WIIson J. Healthy Markets for Global Health: A Market Shaping Primer. 2014;1-65. Available from: https://www.usaid.gov/sites/default/files/documents/1864/healthymarkets_primer.pdf

20. Bennett S, Quick JD, Velásquez JD. Capacity-building and the process of change. Public-Private roles Pharm Sect Implic equitable access Ration drug use [Internet]. 1997;143. Available from:

http://apps.who.int/medicinedocs/pdf/whozip27e/whozip27e.pdf

21. Bennett S, Hanson K, Kadama P, Montagu D (2005) Working with the non-state sector to achieve public health goals. Making health systems work: Working paper no. 2. World Health Organization.

22. Lam F, Abdulwahab A, Houdek J, Adekeye O, Abubakar M, Akinjeji A, et al. Program evaluation of an ORS and zinc scale-up program in 8 Nigerian states. J Glob Health. 2019;9(1).

23. National Population Commission Available online: http://population.gov.ng/ [Assessed 11th August, 2018].

24. United Nations Children Fund. Available online at https://www.unicef.org/infobycountry/nigeria_statistics.html [Assessed 11th August, 2018).

25. http://www.ianphi.org/membercountries/memberinformation/nigeria.html.

26. Clinton health access initiative, shaping local markets to scale-up zinc and oral rehydration salts in Nigeria, 2016. [Online] Available: ht_tp://www_.clintonhealthaccess.org/content/uploads/ 2016/02/Progress-over-aDecade-of-Zinc-and-ORS-Scale-Up.pdf. 2016.

27. Keppel K, Pamuk E, Lynch J, Carter-Pokras O, Kim Insun, Mays V, et al. Methodological issues in measuring health disparities. Vital Health Stat 2. 2005;1-16.

28. Kim M, Garcia AR. Measuring Racial/Ethnic Disparities in Mental Health Service Use Among Children Referred to the Child Welfare System. Child Maltreat. 2016;21(3):218-27.

29. Harper S LJ. Methods for Measuring Cancer Disparities: Using Data Relevant to Healthy People 2010 Cancer-Related Objectives . NCI Cancer Surveillance Monograph Series, Number 6. Bethesda, MD: National Cancer Institute, 2005. 2010; Available from:

http://seer.cancer.gov/publications/disparities2/HealthDisparities2.pdf

30. O’Donnell O, van Doorslaer E, Wagstaff A, Lindelow M. Analyzing Health Equity Using Household Survey Data [Internet]. 2007. Available from: http://elibrary.worldbank.org/doi/book/10.1596/978-0-8213-6933-3

31. Wagstaff A, Paci P, van Doorslaer E. On the measurement of inequalities in health. Soc Sci Med 1991;33:545-57.

32. Barros AJD, Victora CG. Measuring Coverage in $\mathrm{MNCH}$ : Determining and Interpreting Inequalities in Coverage of Maternal, Newborn, and Child Health Interventions. PLoS Med. 2013;10(5).

33. O’Donnell O, Lindelow E van DAWM. Analyzing Health Equity Using Household Survey Data A Guide to Techniques and Their Implementation. The International Bank for Reconstruction and Development / The World Bank. 2008.

34. Doherty JE. Regulating the for-profit private health sector: Lessons from East and Southern Africa. Health Policy Plan. 2015;30(January):i93-102.

35. Larson CP, Saha UR, Nazrul H. Impact monitoring of the national scale up of zinc treatment for childhood diarrhea in Bangladesh: Repeat ecologic surveys. PLoS Med. 2009;6(11). 
36. Tao Y, Bhattacharjya D, Heching AR, Vempaty A, Singh M, Lam F, et al. Effectiveness of peer detailing in a diarrhea program in Nigeria. IBM J Res Dev. 2017;61(6):11-112.

37. Taneja S, Bahl S, Mazumder S, Martines J, Bhandari N, Bhan MK. Impact on inequities in health indicators: Effect of implementing the integrated management of neonatal and childhood illness programme in Haryana, India. J Glob Health. 2015;5(1).

38. Marmot M, Friel S, Bell R, Houwelling TA, Taylor S. Closing the gap in a generation: health equity through action on the social determinants of health. Lancet (London, England). 2008;372:1661-9.

39. Victora CG, Wagstaff A, Schellenberg JA, Gwatkin D, Claeson M, Habicht J. Child survival IV Applying an equity lens to child health and mortality: more of the same is not enough. 2003;362:233-41.

40. Galactionova K, Smith TA, Savigny D De, Penny MA. State of inequality in malaria intervention coverage in sub-Saharan African countries. 2017;(October).

41. Grépin KA. Private Sector An Important But Not Dominant Provider Of Key Health Services In Low- And Middle-Income Countries. Health Aff [Internet]. 2016 Jul 1;35(7):1214-21. Available from:

https://doi.org/10.1377/hlthaff.2015.0862

42. Gwatkin DR, Rutstein S, Johnson K, Suliman E, Wagstaff A, Amouzou A. Socio-economic diff erences in health, nutrition, and population within developing countries-an overview. Produced by the World Bank in collaboration with the Government of the Netherlan.

43. Morgan R, Ensor T, Waters $H$. Performance of private sector health care: implications for universal health coverage. Lancet [Internet]. 2016;388(10044):606-12. Available from: http://dx.doi.org/10.1016/S01406736(16)00343-3

44. Montagu D, Goodman C. Prohibit, constrain, encourage, or purchase: how should we engage with the private health-care sector? Lancet [Internet]. 2016;388(10044):613-21. Available from: http://dx.doi.org/10.1016/S0140-6736(16)30242-2

45. Mujinja PGM, Mackintosh M, Justin-Temu M, Wuyts M. Local production of pharmaceuticals in Africa and access to essential medicines: "Urban bias" in access to imported medicines in Tanzania and its policy implications. Global Health. 2014;

46. Lam F, Abdulwahab A, Houdek J, Adekeye O, Abubakar M, Akinjeji A, et al. Program evaluation of an ORS and zinc scale-up program in 8 Nigerian states. J Glob Health. 2019;9(1).

47. KUMARANAYAKE SVAL. How to do ( or not to do ) ... Constructing socio-economic status indices: how to use principal components analysis. 2018;(June).

\section{Figures}




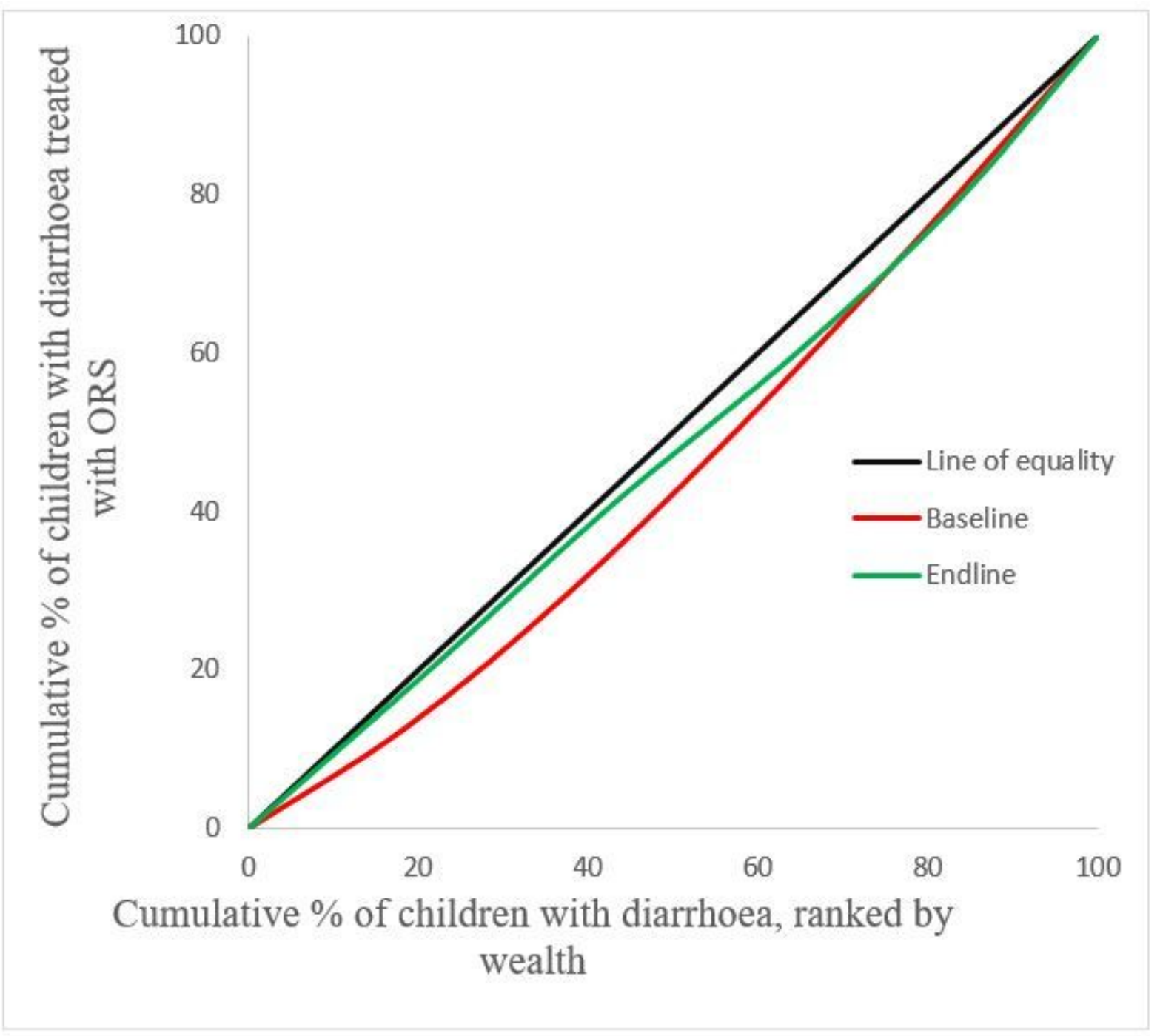

Figure 1

Concentration curve for ORS treatment coverage among socioeconomic groups 


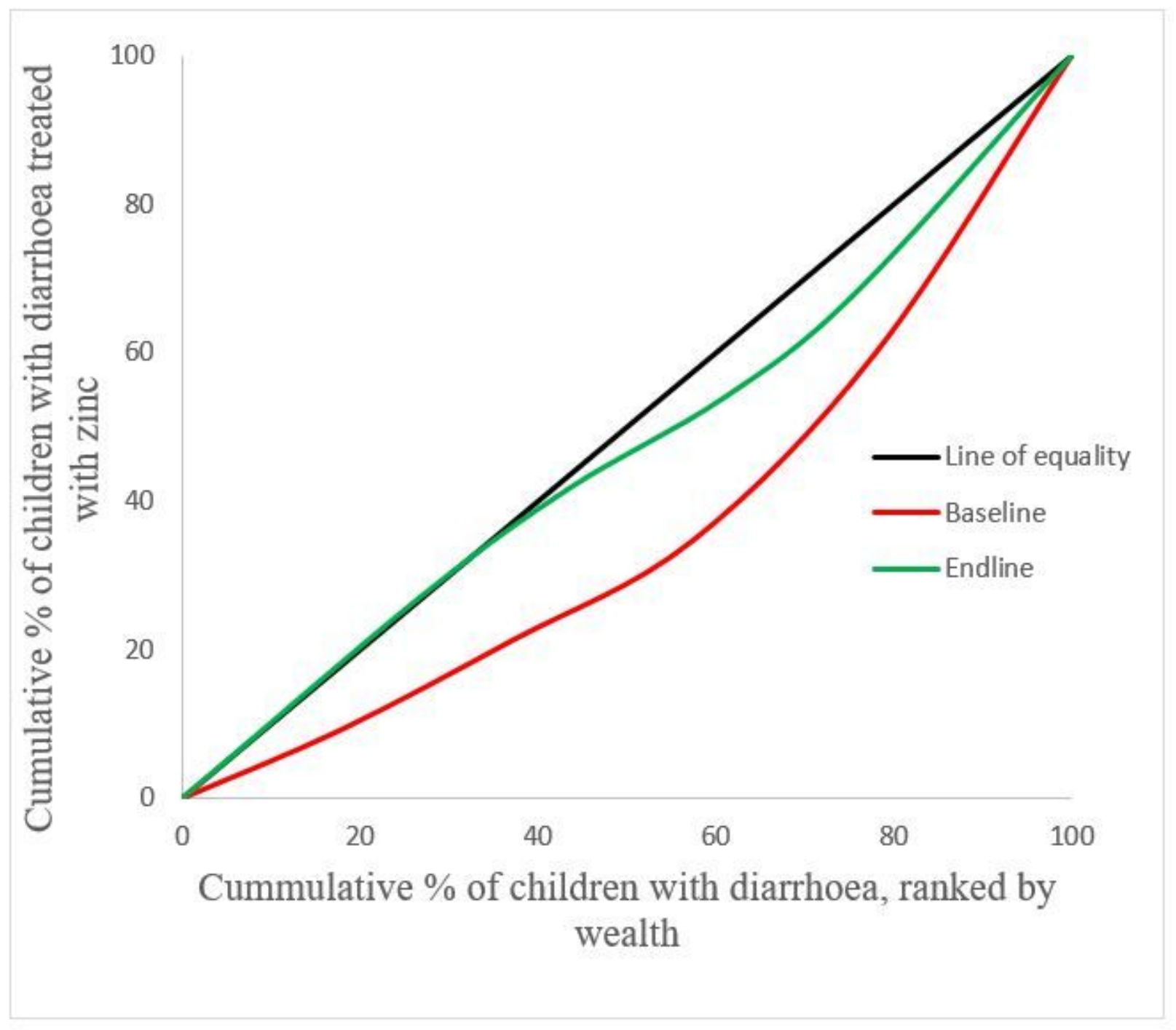

Figure 2

Concentration curve for zinc treatment coverage among socioeconomic groups 